\title{
Coaxial electrospun polyurethane core-shell nanofibers for shape memory and antibacterial nanomaterials
}

\author{
H. T. Zhuo, J. L. Hu* , S. J. Chen \\ Institute of Textiles and Clothing, The Hong Kong Polytechnic University, Hung Hom, Kowloon, Hong Kong, China
}

Received 25 July 2010; accepted in revised form 26 October 2010

\begin{abstract}
A novel kind of shape memory polyurethane (SMPU) nanofibers with core-shell nanostructure is fabricated using coaxial electrospinning. Transmission electron microscopy (TEM) and scanning electron microscopy (SEM) results show that nanofibers with core-shell structure or bead-on-string structure can be electrospun successfully from the core solution of polycaprolactone based SMPU (CLSMPU) and shell solution of pyridine containing polyurethane (PySMPU). In addition to the excellent shape memory effect with good shape fixity, excellent antibacterial activity against both gramnegative bacteria and gram-positive bacteria are achieved in the CLSMPU-PySMPU core-shell nanofiber. Finally, it is proposed that the antibacterial mechanism should be resulted from the PySMPU shell materials containing amido group in $\gamma$ position and the high surface area per unit mass of nanofibers. Thus, the CLSMPU-PySMPU core shell nanofibers can be used as both shape memory nanomaterials and antibacterial nanomaterials.
\end{abstract}

Keywords: nanomaterials, smart polymers, electrospinning, shape memory, antibacterial

\section{Introduction}

Smart polymer ultrafine fibers have gained much attention due to their great potential applications, such as textiles, filtration, catalysis, reinforcement and biomedical use [1-3]. Particularly, polymeric micro/nanofibers with core-shell structure have been attractive in the past decades [4, 5]. Co-axial electrospinning provides an effective and versatile way to fabricate core-shell micro/nanofibers $[4,6$, 7]. This technique can not only be used to spin the unspinnable polymers into ultrafine fiber, but also be used to keep the functionalizing agents like biomolecules and antibacterial agents in the core-shell nanofibers. For example, Liu et al. [8] had developed core-shell nanofibrous mats with a controllable drug-releasing capability for the tissue engineering scaffold. Jiang et al. [9] encapsulated BSA and lysozyme in polycaprolactone (PCL) nanofibers and found the released lysozyme main- tained its structure and bioactivity. Therefore, it is desirable to achieve various functionalizations in the core-shell micro/nanofibers using the coaxial electrospinning.

In addition, shape memory polymers (SMPs) in particular shape memory polyurethanes (SMPUs) were widely studied in the past decades [10-12]. In addition to the excellent shape memory effect, the SMPUs demonstrate functional biocompatibility and had been used in various medical interventions such as vascular stents [13]. Recently, antibacterial activity was reported in the SMPU ionomers by Zhu et al. [14]. Most recently, Chen et al. [15-17] had also synthesized one novel kind of supramolecular SMPUs containing pyridine moieties. Not only thermal-induced shape memory effect (SME) [17], but moisture-sensitive shape memory effect are also achieved in the pyridine containing SMPUs (PySMPUs) [16]. A preliminary investigation sug-

\footnotetext{
${ }^{*}$ Corresponding author, e-mail: tchuj1@inet.polyu.edu.hk
} (c) BME-PT 
gests that the nanofibers based on the PySMPUs exhibits antibacterial activity. However, it is difficult to spin the pure PySMPU/dimethylformamide (DMF) solution into fibers with the conventional electrospinning.

Therefore, the coaxial electrospinning is introduced to fabricate antibacterial nanofiber with core-shell structure in this experiment. The PCL based SMPUs (CLSMPU) or the elastic polyurethanes (TPUs) are designed to provide the certain mechanical properties as the core materials while the PySMPU is introduced as the sheath to exhibit additional properties including antibacterial activity. The preparation and antibacterial activity of SMPU-PySMPU core-shell nanofibers are reported in this communication.

\section{Experimental section}

\subsection{Materials}

DMF bought from Sigma-Aldrich Corporation (U.S.A) was used without any treatment. CLSMPU containing $75 \%$ soft segment content was synthesized by bulk polymerization in our lab according to the literature procedure $[18,19]$. The PySMPU containing various contents of pyridine moieties was synthesized by solution polymerization in our lab according to the literature procedure [15]. For comparison study, TPU based on polytetramethylene glycol with glass transition temperature of $-30^{\circ} \mathrm{C}$ are selected in this study. CLSMPU $\left(M_{\mathrm{n}}=\right.$ $180000)$, TPU $\left(M_{\mathrm{n}}=200000\right.$, bought from Hong Kong HI-Tec Enterprises Limited), PySMPU containing $53 \mathrm{wt} \%$ pyridine moieties (named PUPy53, $\left.M_{\mathrm{n}}=40000\right)$ and PySMPU containing $35 \mathrm{wt} \%$ pyridine moieties and $35 \mathrm{wt} \%$ hard segment (named PUPyMDI35, $\left.M_{\mathrm{n}}=70000\right)$, were prepared to $10 \mathrm{wt} \%$ DMF solutions for electrospinning.

\subsection{Coaxial electrospinning}

In this experiment, for comparison, the CLSMPUPUPy53 and TPU-PUPyMDI53 core-shell nanofibers were prepared using the co-axial electrospinning. The experimental setup for coaxial electrospinning is shown in Figure 1. Both the shell solution and core solution were fed independently with a programmable syringe pump. The feed rates are both set at $0.015 \mathrm{ml} / \mathrm{min}$. A collecting plate was placed on a rotating drum controlled by a stepping motor. The applied voltage was $20 \mathrm{kV}$.

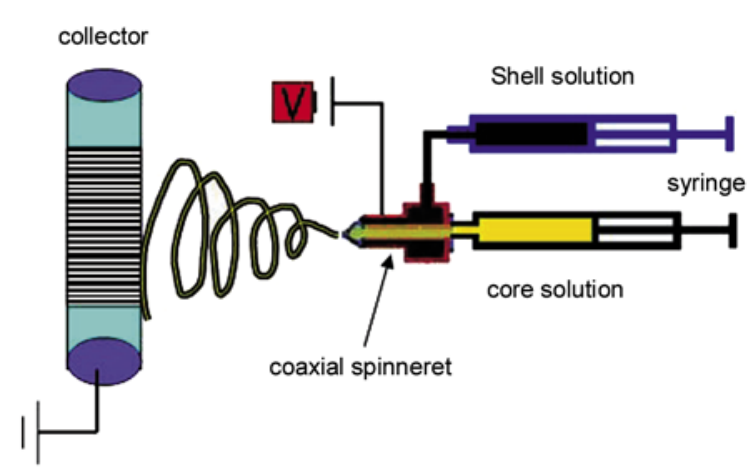

Figure 1. Experimental setup for coaxial electrospinning

\subsection{Characterization}

The surface morphology was observed using a scanning electron microscopy (SEM, S-4700 Hitachi, Japan) with an accelerating voltage of $20.0 \mathrm{kV}$. The core-shell structure was characterized using a transmission electron microscopy (TEM, Tecnai G2 F20 Philips, The Netherlands).

Antibacterial activity against gram-positive bacteria Staphylococcus aureus (S.aureus, ATCC6538) and gram-negative bacteria Klebsiella pneumoniae (K.pneumoniae, ATCC31488) was evaluated qualitatively according to the AATCC test method AATCC147 [14]. In this test, the specimens including corresponding untreated controls of the same material were placed in intimate contact with growth agar which had been previously streaked with test organism. After incubation, a clear area of interrupted growth underneath and along the sides of the test material indicated the antibacterial activity of the specimen. The size of the zone of inhibition and the narrowing of the streaks caused by the presence of the antibacterial agent permitted an estimate of the antibacterial activity.

Thermal-induced shape memory behaviors were characterized with cyclic tensile test method according to the literature method [17]. The test specimens with a width of $5.0 \mathrm{~mm}$ and length of $4.0 \mathrm{~mm}$ for cyclic tensile test are cut directly from the nanofibrous mat. The low temperature ( $T_{\text {low }}$ ) for specimen stretching is about $45^{\circ} \mathrm{C}$ while the high temperature $\left(T_{\text {high }}\right)$ for recovering is about $70^{\circ} \mathrm{C}$. The test was done using an Instron 4466 apparatus with a temperature-controlled chamber; and a personal computer was used to control and record all data. The shape fixity and shape recovery were calculated from the recorded cyclic strain-stress curves [17]. 


\section{Results and discussion}

\subsection{Structure and morphology}

Figure 2 shows the SEM images of CLSMPUPUPy53 and TPU-PUPyMDI35 core-shell nanofibers; and Figure 3 shows their TEM images. It is found in Figure 2 that uniform nanofibers with a diameter ranging from 600 to $1000 \mathrm{~nm}$ are fabricated in the CLSMPU-PUPy53 nanofiber. The TEM images confirm that the resultant CLSMPUPUPy53 nanofibers have core-shell structure. The diameter of CLSMPU core nanofiber is changed from 250 to $320 \mathrm{~nm}$ while the sheath has a diameter of more than $600 \mathrm{~nm}$. The interface between core material and sheath materials is clear since they are spun from different polymer. However, when the core material is spun from TPU/DMF solution and the shell material is spun from PUPyMDI35 materials, the resultant nanofibers not only form coreshell structure, but beads with average diameters of $1.5 \mu \mathrm{m}$ are also observed on the core nanofibers. The distance within one bead is changed from 2.5 to $3.5 \mu \mathrm{m}$. It is also observed in Figure 2b. that clear interface is formed between the bead and the continuous core fiber. The core fiber threads the beads like a string. In this system, the core material is TPU while the shell material is PUPyMDI35. Thus, the beads should be formed by the PUPyMDI35 material due to their bad spinnability. Therefore, the coaxial electrospinning method can be used to fabricate core-shell micro/nanofibers and beads-onstring micro/nanofibers by adjusting the composition of core materials and shell materials. Comparing with the bulk film, the surface area per unit

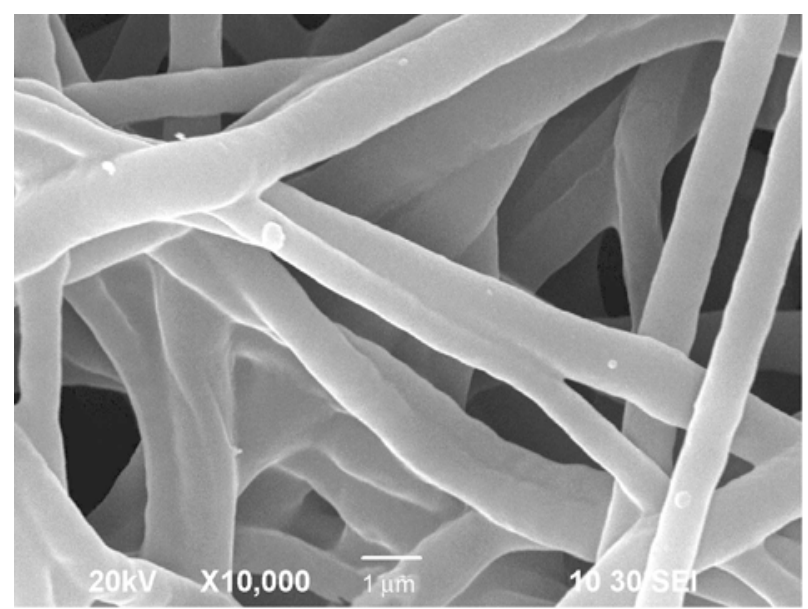

a)

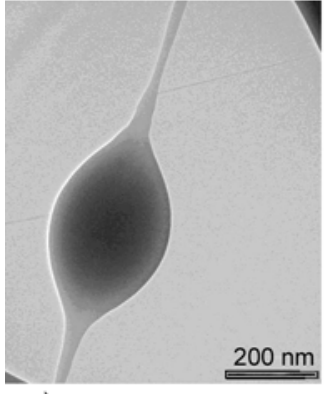

Figure 3. TEM images of (a) SMPU-PUPy53 and (b) TPUPUPyMDI35 core-shell nanofiber

mass is improved greatly in both core-shell structure and bead-on-string structure nanofibers.

\subsection{Thermal-induced shape memory properties}

Figure 4 shows the cyclic strain-stress curve of CLSMPU-PUPy53 core-shell nanofibrous mat. It

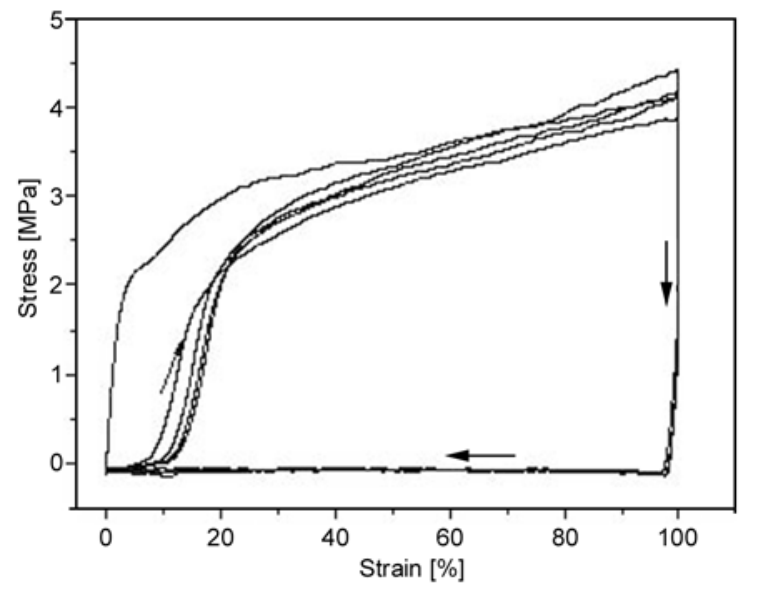

Figure 4. Stress-strain curve of CLSMPU/PUPy53 coreshell microfibrous mat

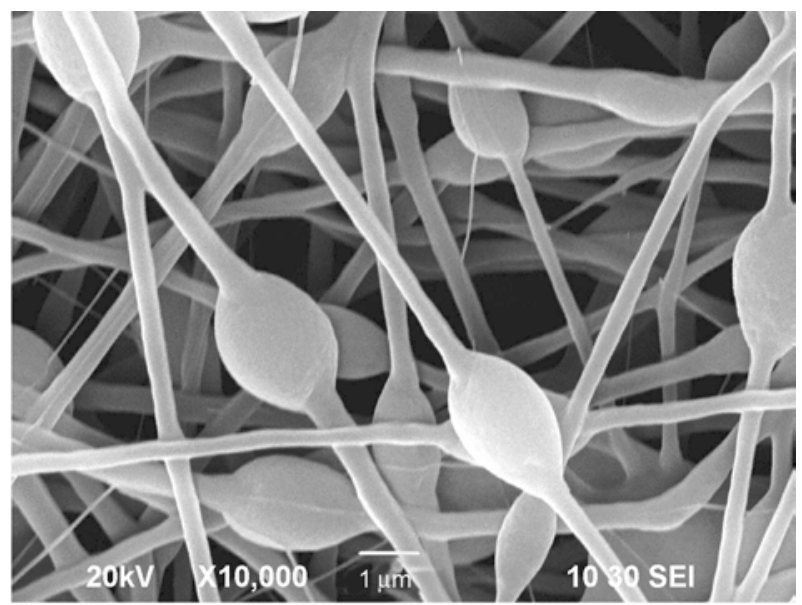

b)

Figure 2. SEM images of (a) SMPU-PUPy53 and (b) TPU-PUPyMDI35 core-shell nanofiber 
was reported that the transition temperature of CLSMPU nanofiber is about $46.83^{\circ} \mathrm{Cwhile}$ the transition temperature of PUPy 53 is about $56^{\circ} \mathrm{C}$ [17]. The CLSMPU nanofiber usually shows unsatisfying shape fixity, less than $80 \%$ [20, 21]. However, when the CLSMPU nanofiber is coaxial electrospun into core-shell nanofibers with the sheath of PUPy53, the shape fixity is increased significantly to above $95 \%$ as shown in Figure 4. The shape recovery at the first cycle is still beyond $90 \%$ in the CLSMPU-PUPy53 core-shell nanofiber under the recovery temperature of $70^{\circ} \mathrm{C}$. This behavior is very similar to the thermal-induced shape memory behavior of PUPy53 bulk film, which exhibits not only high shape fixity, but also good shape recovery [17]. This is due to the fact that the PUPy53 polymer has much high glassy modulus as reported by Chen et al. [17]. The PUPy53 sheath plays key role on the thermalinduced SME in this CLSMPU-PUPy53 core-shell nanofiber mat.

\subsection{Antibacterial activity}

Table 1 summarizes the result of antibacterial activity of CLSMPU-PUPy53 core-shell nanofibrous mat as compared with the pure CLSMPU nanofibrous mat and the PUPy53 bulk film. It is found that no growth of $S$. aureus and $K$. pneumoniae bacteria is observed directly underneath the CLSMPUPUPy53 core-shell nanofibrous mat. However, growth of $S$. aureus and K. pneumoniae bacteria is observed directly underneath the PUPy53 bulk film and the pure CLSMPU nanofibrous mat. Additionally, $0 \mathrm{~mm}$ clear zone of inhibition is observed in the CLSMPU-PUPy53 core-shell nanofibrous mat. This observation suggests that the CLSMPUPUPy53 core-shell nanofibrous mat has the acceptable antibacterial activity against both gram-positive and gram-negative bacteria while the CLSMPU nanofibrous mat and PUPy53 bulk polymer show unacceptable antibacterial activity. Moreover, there is no detectable diffusion of antibacterial agent from the CLSMPU-PUPy53 core-shell fibrous mat, i.e. the coaxial electrospinning provides a versatile method to encapsulate immobilized antibacterial agents in the core-shell micro/nanofibers. The antibacterial mechanism of this new kind of core-shell nanofibers may be different from the mechanism of Ag-doped antibacterial nanofibers [22, 23]. One reason is that the PySMPU like PUPy53 and PUPyMDI35 contains large fraction of BINA unit which have an amido group in $\gamma$ position, and has important anti-tubercular, anti-pyretic and antibacterial properties [24]. Moreover, the microorganism contact surface area has been improved greatly after the PySMPU was electrospun into micro/nanofibers with core-shell structure or beads-on-string structure.

\section{Conclusions}

Novel core-shell micro/nanofibers are fabricated from the SMPU/DMF core solution and PySMPU/ DMF shell solution using the coaxial electrospinning method in this experiment. Results show that both core-shell structure and bead-on-string structure can be formed in the core-shell micro/nanofiber by adjusting the core solution and shell solution. In addition to the excellent shape memory behaviors with good shape fixity, the CLSMPUPySMPU core-shell nanofibrous mat is tested to show excellent antibacterial activity against both gram-negative bacteria and gram-positive bacteria. The antibacterial mechanism should be resulted from the PySMPU shell materials and the high surface area per unit mass of nanofibers. Thus, the CLSMPU-PySMPU core shell nanofibers are proposed for both shape memory nanomaterials and antibacterial nanomaterials.

Table 1. Antibacterial activity testing result using AATCC 147-2004

\begin{tabular}{|c|c|c|c|}
\hline \multirow[b]{2}{*}{ Test microorganism } & \multicolumn{3}{|c|}{ Antibacterial activity } \\
\hline & $\begin{array}{l}\text { PUPy53 } \\
\text { bulk film }\end{array}$ & $\begin{array}{c}\text { CLSMPU } \\
\text { nanofiber mat }\end{array}$ & $\begin{array}{c}\text { CLSMPU-PUPy53 } \\
\text { core-shell nanofiber mat }\end{array}$ \\
\hline Staphylococcus aureus & $\begin{array}{l}\text { Growth was observed directly } \\
\text { underneath the tested specimen }\end{array}$ & $\begin{array}{l}\text { Growth was observed directly } \\
\text { underneath the tested specimen }\end{array}$ & $\begin{array}{l}\text { No growth was observed directly under- } \\
\text { neath the tested specimen with } 0 \text { mm clear } \\
\text { zone }\end{array}$ \\
\hline Klebsiella pneumoniae & $\begin{array}{l}\text { Growth was observed directly } \\
\text { underneath the tested specimen }\end{array}$ & $\begin{array}{l}\text { Growth was observed directly } \\
\text { underneath the tested specimen }\end{array}$ & $\begin{array}{l}\text { No growth was observed directly under- } \\
\text { neath the tested specimen with } 0 \text { mm clear } \\
\text { zone }\end{array}$ \\
\hline
\end{tabular}




\section{Acknowledgements}

This work was financially supported by the Hong Kong RGC project G-T881 and the Hong Kong Polytechnic University Niche Area Research Funding Scheme project JBB6M. The authors wish to express their gratitude for the generous support.

\section{References}

[1] Danno T., Matsumoto H., Nasir M., Shimizu S., Minagawa M., Kawaguchi J., Horibe H., Tanioka A.: Fine structure of PVDF nanofiber fabricated by electrospray deposition. Journal of Polymer Science Part B: Polymer Physics, 46, 558-563 (2008).

DOI: $10.1002 /$ polb.21391

[2] Greiner A., Wendorff J. H.: Electrospinning: A fascinating method for the preparation of ultrathin fibers. Angewandte Chemie, International Edition, 46, 56705703 (2007). DOI: 10.1002/anie.200604646

[3] Huang Z-M., Zhang Y-Z., Kotaki M., Ramakrishna S.: A review on polymer nanofibers by electrospinning and their applications in nanocomposites. Composites Science and Technology, 63, 2223-2253 (2003). DOI: 10.1016/S0266-3538(03)00178-7

[4] Zhang J-F., Yang D-Z., Xu F., Zhang Z-P., Yin R-X., Nie J.: Electrospun core-shell structure nanofibers from homogeneous solution of poly(ethylene oxide)/ chitosan. Macromolecules, 42, 5278-5284 (2009). DOI: $10.1021 / \mathrm{ma} 900657 \mathrm{y}$

[5] Li W., Liu C., Zhou Y. X., Bai Y., Feng X., Yang Z. H., Lu L. H., Lu X. H., Chan K. Y.: Enhanced photocatalytic activity in anatase $/ \mathrm{TiO}_{2}(\mathrm{~B})$ core-shell nanofiber. Journal of Physical Chemistry C, 112, 20539-20545 (2008). DOI: $10.1021 / j p 808183 q$

[6] Sun Z. C., Zussman E., Yarin A. L., Wendorff J. H., Greiner A.: Compound core-shell polymer nanofibers by co-electrospinning. Advanced Materials, 15, 19291932 (2003).

DOI: $10.1002 / \mathrm{adma} .200305136$

[7] Moghe A. K., Gupta B. S.: Co-axial electrospinning for nanofiber structures: Preparation and applications. Polymer Reviews, 48, 353-377 (2008).

DOI: 10.1080/15583720802022257

[8] Liu S. P., Li X. Q., Su Y., Tan L. J., Zhang Y., Chen Y. M.: Study of electrospun PLLACL nanofibrous mats for drug delivery system. Materials Science Forum, Materials Research, 610-613, 1319- 1322 (2009). DOI: 10.4028/www.scientific.net/MSF.610-613.1319

[9] Jiang H. L., Hu Y. Q., Li Y., Zhao P. C., Zhu K. J., Chen W. L.: A facile technique to prepare biodegradable coaxial electrospun nanofibers for controlled release of bioactive agents. Journal of Controlled Release, 108, 237-243 (2005).

DOI: $10.1016 / \mathrm{j} . j$ conrel.2005.08.006
[10] Gunes I. S., Jana S. C.: Shape memory polymers and their nanocomposites: A review of science and technology of new multifunctional materials. Journal of Nanoscience and Nanotechnology, 8, 1616-1637 (2008).

DOI: $10.1166 / \mathrm{jnn} .2008 .038$

[11] Liu C., Qin H., Mather P. T.: Review of progress in shape-memory polymers. Journal of Materials Chemistry, 17, 1543-1558 (2007).

DOI: $10.1039 / \mathrm{B} 615954 \mathrm{~K}$

[12] Ratna D., Karger-Kocsis J.: Recent advances in shape memory polymers and composites: A review. Journal of Materials Science, 43, 254-269 (2008). DOI: $10.1007 / \mathrm{s} 10853-007-2176-7$

[13] Cabanlit M., Maitland D., Wilson T., Simon S., Wun T., Gershwin M. E., Van de Water J.: Polyurethane shape-memory polymers demonstrate functional biocompatibility in vitro. Macromolecular Bioscience, 7, 48-55 (2007). DOI: $10.1002 / \mathrm{mabi} .200600177$

[14] Zhu Y., Hu J., Yeung K.: Effect of soft segment crystallization and hard segment physical crosslink on shape memory function in antibacterial segmented polyurethane ionomers. Acta Biomaterialia, 5, 33463357 (2009).

DOI: $10.1016 /$ j.actbio.2009.05.014

[15] Chen S. J., Hu J. L., Yuen C-W., Chan L. K.: Supramolecular polyurethane networks containing pyridine moieties for shape memory materials. Materials Letters, 63, 1462-1464 (2009). DOI: 10.1016/j.matlet.2009.03.028

[16] Chen S., Hu J., Yuen C-W., Chan L.: Novel moisturesensitive shape memory polyurethanes containing pyridine moieties. Polymer, 50, 4424-4428 (2009).

DOI: $10.1016 /$ j.polymer.2009.07.031

[17] Chen S., Hu J., Zhuo H., Yuen C., Chan L.: Study on the thermal-induced shape memory effect of pyridine containing supramolecular polyurethane. Polymer, 51, 240-248 (2010).

DOI: 10.1016/j.polymer.2009.11.034

[18] Chen S., Hu J., Liu Y., Liem H., Zhu Y., Liu Y.: Effect of SSL and HSC on morphology and properties of PHA based SMPU synthesized by bulk polymerization method. Journal of Polymer Science Part B: Polymer Physics, 45, 444-454 (2007).

DOI: $10.1002 /$ polb.21046

[19] Chen S. J., Hu J. L., Liu Y. Q., Liem H. M., Zhu Y., Meng Q. H.: Effect of molecular weight on shape memory behavior in polyurethane films. Polymer International, 56, 1128-1134 (2007).

DOI: $10.1002 /$ pi.2248

[20] Zhuo H. T., Hu J. L., Chen S. J., Yeung L. P.: Preparation of polyurethane nanofibers by electrospinning. Journal of Applied Polymer Science, 109, 406-411 (2008).

DOI: $10.1002 /$ app. 28067 
[21] Zhuo H. T., Hu J. L., Chen S. J.: Electrospun polyurethane nanofibres having shape memory effect. Materials Letters, 62, 2074-2076 (2008).

DOI: 10.1016/j.matlet.2007.11.018

[22] Yuan J., Geng J., Xing Z., Shen J., Kang I-K., Byun H.: Electrospinning of antibacterial poly(vinylidene fluoride) nanofibers containing silver nanoparticles. Journal of Applied Polymer Science, 116, 668-672 (2010).

DOI: $10.1002 / a p p .31632$
[23] Son B., Yeom B-Y., Song S. H., Lee C-S., Hwang T. S.: Antibacterial electrospun chitosan/poly(vinyl alcohol) nanofibers containing silver nitrate and titanium dioxide. Journal of Applied Polymer Science, 111, 2892-2899 (2009).

DOI: 10.1002/app.29233

[24] Akalin E., Yilmaz A., Akyuz S.: Vibrational analysis of isonicotinamide. Journal of Molecular Structure, 744-747, 881-886 (2005).

DOI: $10.1016 /$ j.molstruc.2004.11.077 